\title{
Accurate Referential Communication and its Relation with Private and Social Speech in a Naturalistic Context
}

\author{
Dolors Girbau \\ Jaume I University
}

\author{
Humbert Boada \\ University of Barcelona
}

\begin{abstract}
Research into human communication has been grouped under two traditions: referential and sociolinguistic. The study of a communication behavior simultaneously from both paradigms appears to be absent. Basically, this paper analyzes the use of private and social speech, through both a referential task (Word Pairs) and a naturalistic dyadic setting (Lego-set) administered to a sample of 64 children from grades 3 and 5. All children, of 8 and 10 years of age, used speech that was not adapted to the decoder, and thus ineffective for interpersonal communication, in both referential and sociolinguistic communication. Pairs of high-skill referential encoders used significantly more task-relevant social speech, that is, cognitively more complex, than did low-skill dyads in the naturalistic context. High-skill referential encoder dyads showed a trend to produce more inaudible private speech than did low-skill ones during spontaneous communication. Gender did not affect the results.

Keywords: private speech, social speech, referential communication
\end{abstract}

La investigación sobre comunicación humana se agrupa entorno a dos tradiciones: referencial y sociolingüística. Al parecer nunca se ha estudiado una conducta comunicativa simultáneamente desde ambos paradigmas. Básicamente este artículo analiza el uso del lenguaje privado y social, mediante una tarea referencial (Pares de Palabras) y una situación natural diádica (Lego), en una muestra de 64 niños/as de tercer y quinto cursos de primaria. Todos los niños/as de 8 y 10 años de edad produjeron un tipo de lenguaje no adaptado al descodificador, o sea ineficaz para la comunicación interpersonal, tanto en la comunicación referencial como en la sociolingüística. Las díadas formadas por los mejores codificadores referenciales usaron significativamente más lenguaje social pertinente a la tarea, o sea cognitivamente más complejo, que las díadas peores, en el contexto natural de comunicación espontánea. Las díadas de mejores codificadores referenciales mostraron una tendencia a producir más lenguaje privado inaudible que las peores, durante la comunicación espontánea. La variable sexo no influyó significativamente en los resultados.

Palabras clave: habla privado, habla social, comunicación referencial

This research was funded by two grants from the Institut de Sociolingüística Catalana (Direcció General de Política Lingüística Generalitat de Catalunya) and one grant from the Divisió de Ciències de la Salut (University of Barcelona), all to the first author.

Address all correspondence to: Dolors Girbau, Department of Basic Psychology, University Jaume I, Campus Riu Sec, 12080 Castelló. Spain. E-mail address: girbau@psb.uji.es 
Human communication researchers have devoted a great effort to answer a central and complex question: how can one attain accurate communication? Two well-studied processes have been considered crucial to achieve this goal: the development of social speech and the internalization of private speech (Flavell, 1964/1966; Piaget, 1923/1968; Vygotsky, 1934/1987; Watson, 1919/1983; Wertsch, 1985).

In order to solve this question, many tasks, settings, and procedures have emerged from different methodological approaches. Basically, communication research can be grouped under two traditions: referential and sociolinguistic (Dickson, 1981). The main difference between them is that, traditionally, the referential paradigm examines communication via experimental tasks, whereas sociolinguistic research uses natural settings and observational methodology for data collection-that is why it is also called the "naturalistic approach." Usually, scientists have focused on one of the two traditions, although some attempts have been made to reduce the distance between them (see Girbau, 2002a, Schober \& Brennan, 2002, and Yule, 1997, for a review). Some of these attempts have allowed participants to communicate naturally while carrying out a laboratory task (e.g., Boada \& Forns, 1997; Garrod \& Clark, 1993). Potentially, another way of drawing the two paradigms closer together is to administer tasks from both paradigms to just one sample of participants. This strategy may well produce more reliable conclusions than one based exclusively on one of the approaches and may also help to predict natural communicative behaviors from laboratory tasks.

In fact, the two above-mentioned paradigms frequently present contrasting results on similar topics. For instance, studies on referential communication report that the skills necessary for efficient communication are acquired later than claimed by sociolinguistic researchers (Dickson, 1981). This may be partially due to the fact that the referential approach has overemphasized results indicating communicative incompetence, in spite of the presence of more positive data in the reports. However, differences in results from both traditions can also be related to discrepancies in methodology. Indeed, the articulation of both perspectives is necessary for a deeper understanding of children's oral communication skills and will also contribute to developing a clearer and more comprehensive theoretical setting than the current one (Erickson, 1981). Therefore, if we are really interested in generalizing conclusions from one paradigm to another, then we should design "badly needed" studies that relate them to one another (Dickson, 1981, p. 7).

The first important attempts to determine which processes are responsible for inaccurate human communication arose from the studies on the originally socalled "egocentric speech" — nowadays, termed private speech. This phenomenon has been analyzed separately in both traditions. Since the term and notion of egocentric speech was first coined (Piaget, 1923/1968) and reinterpreted (Vygotsky, 1934/1987), several new labels and concepts have evolved (see Girbau, 1996, for a critical review). Its complexity has been reported by numerous authors, some of whom have even expressed the need for studies with solid psychometric considerations in task construction and data collection in order to infer egocentric behavior (Waters \& Tinsley, 1985).

Integrating aspects of Flavell's (1964/1966) and Piaget's (1923/1968) conceptual viewpoints, private speech is defined here as an emission that is neither addressed nor adapted to the decoder, unlike social speech, which is speech addressed to the decoder. These are the definitions that will be used here in focusing on the naturalistic approach. With respect to the referential paradigm, social speech is required from the encoder, who can, however, emit inaccurate messages when addressing a decoder, showing a deficient adaptation to the decoder. Therefore, the notion of nonadaptation to the decoder in the communication can be investigated from both perspectives, as will be detailed below.

In the referential tradition, Asher and Oden (1976) investigated the presence of 'egocentrism' in children's referential communication through a Word Pairs task, requiring the comparison process between the one-word message, the referent, and the nonreferent, following the stochastic model established by Rosenberg and Cohen (1964). According to the former authors, the children did not engage in an egocentric comparison process and did not give their messages a private meaning, as these messages were as effective for them as for a sample of adult decoders (college students in Introductory Child Psychology classes). Two decades later, this conclusion was challenged by a study that administered the same task to children of the same age (grades 3 and 5), who did use social speech with private meaning; that is, speech addressed to the decoder but only adapted to oneself, engaging in an egocentric form of comparison process, (Girbau \& Boada, 1996). In fact, highskill and low-skill encoders identified significantly more referents with their own messages than did a sample of science graduate adults using these children's messages. Another study (Glucksberg, Krauss \& Weisberg, 1966), with some important methodological differences, also accepted the existence of idiosyncratic messages with private, but not public, meaning emitted by younger children in a different referential task.

In two of the reports (Asher \& Oden, 1976; Girbau \& Boada, 1996), a criterion for classifying types of encoders by dividing the whole sample into high-skill and low-skill encoders was used, defining low-skill encoders as the most inaccurate in communicating with others, as they produced more messages that were not adapted to a standard decoder. On the other hand, referential communication performance does not generally seem to be affected by sex (see Dickson, 1982, for a review), despite very few exceptions in some specific aspects (e.g., Lloyd, Camaioni \& Ercolani, 1995). 
As far as the naturalistic approach is concerned, there is a considerable amount of research on private speech. Many of these studies have focused on the age range from 4 to 8 years, and hardly any of them has analyzed social speech through subcategories, due mainly to a pronounced preference for nonsocial settings (see Diaz \& Berk, 1992, and Fuson, 1979, for a review). However, some authors have emphasized the importance of private speech among adults (John-Steiner, 1992; Looft, 1972). Within the scarce research based on a dyadic-peer interactive context, 10year-olds used significantly more task-relevant social speech and also significantly less task-irrelevant social speech than 8-year-olds, whereas both groups-over age 7showed a clear persistence of external private speech (Girbau, 2002c). From a different approach, evidence of superficial coordination processes was found in a younger group (7-8-year-olds), as opposed to two older groups (910 and 11-12 years old)—with deep coordination processes -in an analysis of only social speech (Garrod \& Clark, 1993).

This last conclusion is at variance with the findings of classical authors such as Piaget (1923/1968) and Vygotsky (1934/1987). According to Piaget, egocentric speech tends to disappear noticeably after age seven, whereas Vygotsky (1934/1987) argues that, as it atrophies, it is transformed into inner speech at a similar age. Nevertheless, Vygotsky (1934/1987), despite considering this internalization a gradual process that goes on with age, explicitly denied the existence of any kind of semi-soundless speech, as Watson (1919/1983) claimed. This last author stated that there is an intermediate link between overt speech (aloud) and implicit language (or silent talking), which is whispered language. Therefore, unifying part of both authors' theories, private speech could be viewed as external speech (aloud) that it is progressively transformed into inner speech (silent) through the intermediate link called inaudible private speech or whispering (inaudible to the other interlocutor). Silence will be analyzed from this approach in the present study, leaving aside other possible interpretations. Several previous studies that included participants of ages over 7 years old have reported significantly more use of inaudible private speech in older participants than in younger ones from a non-peer context (Berk \& Garvin, 1984; Kohlberg et al., 1968) and a dyadic one (Girbau, 2002c).

In view of this, the development of a new approach to the phenomenon seems to be called for. The general aim of the present study is to test how accurate referential communication is related with private and social speech in a dyadic naturalistic context; in other words, to analyze the deficient adaptation to the decoder from both referential and sociolinguistic communication in 8- and 10-year-olds. Specifically, the present study is focused on three hypotheses that integrate both traditions in communication research to better understand the cognitive development of children. First, all children will produce inaccurate referential messages - addressed but not adapted to a standard decoder-in the Word Pairs task and will also produce external private speech in the naturalistic dyadic setting, which shows their difficulty of adapting to the other person from both paradigms. Second, high-skill referential encoder dyads will internalize private speech earlier than will low-skill ones during spontaneous communication, and this effect may increase with age. Third, high-skill referential encoder dyads will use a cognitively more complex social speech (that is, more taskrelevant) than will low-skill ones in the naturalistic context, and this effect may increase with age. Lastly, it would be interesting to determine the relative distribution of the speech categories according to the dyadic types of referential encoder.

\section{Method}

\section{Participants}

Sixty-four children, 32 from third grade and 32 from fifth grade, from a middle-class school in Barcelona participated in the study. The mean ages were 8 years and 8 months ( $S D=3$ months, ranging from $8 ; 2$ to $9 ; 2$ ) and 10 years and 8 months $(S D=3$ months, ranging from 10;2$11 ; 2)$, respectively. Data were collected at the school by the first author. An intelligence test of $g$ factor (Cattell 2-A, Cattell \& Cattell, 1973/1986) was administered collectively in each of the 4 class groups ( 2 classrooms for each grade) to 97 pupils -49 in third grade and 48 in fifth grade. The IQ of the sample ranged from 92 to $122(M=107.64, S D$ $=7.84$ ), excluding the most extreme scores. The selection was ratified with the criteria of the respective teachers and the school psychologist. As for the sex variable, 32 were girls and 32 boys.

The children of the sample carried out two tasks. First, a referential communication task was administered individually and after it was completed, a naturalistic communication task was performed in dyads.

\section{Referential Communication}

\section{Task}

The experimenter administered a Word Pairs task, which consisted of 30 word pairs, each printed on a $3 \times 5$-inch index card. Each pair contained a referent (underlined) and a semantically similar nonreferent. They were originally used in English by Cohen and Klein (1968) within a stochastic model (Rosenberg \& Cohen, 1964). (See Table 1). Therefore, we translated the majority and adapted only a few to Catalan (Table 1), endeavoring not to affect the relative degree of association between the referent and the nonreferent (based on the agreement between two judges). 
Table 1

Word Pairs in English and Catalan

\begin{tabular}{|c|c|c|}
\hline \multicolumn{3}{|l|}{ cow-horse } \\
\hline 1. like-love ${ }^{\mathrm{a}}$ & 11.fur-hair ${ }^{\mathrm{a}}$ & 21.mitten-glove ${ }^{b}$ \\
\hline 2. sound-noise ${ }^{b}$ & 12.river-ocean ${ }^{\mathrm{b}}$ & 22.road-street ${ }^{b}$ \\
\hline 3. sleep-rest ${ }^{\mathrm{a}}$ & 13. say-tell $^{\mathrm{b}}$ & 23. plant-flower ${ }^{b}$ \\
\hline 4. dog-puppy ${ }^{b}$ & 14.rubbers-boots ${ }^{\mathrm{b}}$ & 24.mad-angry ${ }^{\mathrm{a}}$ \\
\hline 5. music-song ${ }^{\text {a }}$ & 15.child-baby ${ }^{b}$ & 25.glass-cup ${ }^{a}$ \\
\hline 6. city-town ${ }^{a}$ & 16. big-large $^{a}$ & 26. write-print ${ }^{\mathrm{b}}$ \\
\hline 7. bread-roll ${ }^{\mathrm{a}}$ & 17.dish-plate ${ }^{b}$ & 27.world-earth ${ }^{\mathrm{b}}$ \\
\hline 8. hot-warm ${ }^{\mathrm{a}}$ & 18.hill-mountain ${ }^{\mathrm{a}}$ & 28.ship-boat ${ }^{b}$ \\
\hline 9. crayon-chalk ${ }^{\mathrm{b}}$ & 19.watch-clock ${ }^{\mathrm{a}}$ & 29. wash-clean ${ }^{a}$ \\
\hline 10. short-small ${ }^{\mathrm{b}}$ & 20.cook-bake ${ }^{a}$ & 30.wheel-tire ${ }^{\mathrm{a}}$ \\
\hline \multicolumn{3}{|l|}{ vaca-cavall } \\
\hline 1. agradar-estimar $^{\mathrm{a}}$ & 11.pèl-cabell ${ }^{\mathrm{a}}$ & 21.manyopla-guant ${ }^{\mathrm{b}}$ \\
\hline 2. so-soroll ${ }^{\mathrm{b}}$ & 12.riu-oceà ${ }^{b}$ & 22.carretera-carrer ${ }^{\mathrm{b}}$ \\
\hline 3. dormir-descansar ${ }^{\mathrm{a}}$ & 13.dir-narrar ${ }^{b}$ & 23.planta-flor ${ }^{\mathrm{b}}$ \\
\hline 4. gall-pollet ${ }^{\mathrm{b} *}$ & 14. descansos-botes ${ }^{b}$ & 24. furiós-enfadat ${ }^{\mathrm{a}}$ \\
\hline 5. música-cançóa & 15.nen-bebè ${ }^{b}$ & 25.vas-taça ${ }^{a}$ \\
\hline 6. ciutat-poble ${ }^{a}$ & 16.gran-enorme ${ }^{a}$ & 26.escriure-resseguir ${ }^{b^{*}}$ \\
\hline 7.pa-1longuet ${ }^{\mathrm{a}^{*}}$ & 17.vaixella-plat ${ }^{\mathrm{b}^{*}}$ & 27.món-terra ${ }^{b}$ \\
\hline 8. calent-tebi ${ }^{\mathrm{a}}$ & 18.turó-muntanya ${ }^{\mathrm{a}}$ & 28.vaixell-barca ${ }^{\text {b }}$ \\
\hline 9. 1lapis-guix $^{b}$ & 19.despertador-rellotge $\mathrm{a}^{\mathrm{a}^{*}}$ & 29.rentar-netejar ${ }^{\mathrm{a}}$ \\
\hline 10. curt-petit ${ }^{b}$ & 20.cuinar-rostir ${ }^{\mathrm{a}}$ & 30.roda-pneumàtic ${ }^{\mathrm{a}}$ \\
\hline
\end{tabular}

Note. The word pairs are shown in their original order of presentation. Superscripts $a$ and $b$ designate the 2 subsets.

*Adapted items whose translations in English are: 4.cock-chick, 7.bread-bread roll, 17.dishes-dish, 19.alarm clock-clock and 26.write-repass.

The children provided clues for all 30 word pairs (see Procedure); the task was part of a more extensive research project (see Girbau \& Boada, 1996, for more details). Both subsets of 15 word pairs have been found to present similar difficulty (Asher \& Oden, 1976; Asher \& Parke, 1975). For the present study, the 15 pairs of the subset $a$ will be considered (see Table 1), which was the one used for selfcommunication in a previous experiment (subset $b$ was just used to control memory influence in that former study).

\section{Procedure}

The task was administered individually, following the procedure of Asher and Oden (1976). The experimenter gave the same instructions to each child and made sure that they had understood. Children communicated with an imaginary listener, a procedure used in previous studies (Asher \& Parke, 1975; Kingsley, 1971; Shantz \& Wilson, 1972), which have indicated the absence of conceptual difficulty for elementary school-children; (Asher \& Oden, 1976).

\section{Instructions}

The experimenter told the child:

We're going to play a game. Here we have two words [the experimenter points to a $3 \times 5$-inch index card with the sample pair vaca-cavall (cow-horse)]. One of the words is underlined. This is the word that you are thinking of. Let's pretend that there is a person sitting over there. [The experimenter points to the other side of the table.] This person sees the two words, but doesn't know which word is underlined. They look like this to him [the experimenter turns the card over and shows the child the same two words with neither word underlined]. So, he doesn't know which word you are thinking of. So, think of a clue that would help this person guess which word is underlined. Do you know what a clue is? [If the child said no, the experimenter explained, "A clue is a hint".] The clue has to be one word and it cannot rhyme. Remember, the other person sees both words, and you want him to guess which word is underlined. Can you tell me how the game works?

\section{Test to check child's comprehension}

Before starting, the children were asked to include the following elements in their explanation: (a) the other person has the same words as the child has in front of him; (b) the child knows which word is underlined, but the other person does not; and (c) the child has to give a one-word clue to help the other person choose which word is underlined. If the participant left out any of these elements, the experimenter checked the child's understanding with 
questions about each element: (a) "What does the other person have in front of him/her?"; (b) "Does the other person know which word is underlined?"; (c) "What do you have to do?" If the participant's responses were vague or uncertain, the experimenter repeated the instructions and the test to check comprehension.

The experimenter then read each of the 30 word pairs aloud, showing each index card to the child. The child emitted a clue for each pair, which was noted by the experimenter.

\section{Ratings of Message Quality and Classification of Encoders}

Children were classified as high- or low-skill encoders in order to compare the encoding performance of these two groups, following a classification procedure similar to the one used by Asher and Oden (1976). Participants were grouped on the basis of ratings of message quality expressed by three judges, who were graduates and blind to the aim of the experiment ( 2 female and 1 male). The judges were trained using word pairs with clues that differed from those used in the experiment. They had to look at each word pair, (of the subset $a$ ) with the referent underlined, and rate the child's clue as ineffective or as effective communication to a standard decoder. That is, a clue should be rated as effective when it would allow a standard decoder (and not only the own rater) to guess the referent. From these three judges' ratings of the 960 clues, a generalized kappa coefficient of $k=.82$ was obtained, being between any two observers: $k=.81, k=.81, k=$ .84 ; with $p<.01$.

Each encoder also received a score based on the mean of clues out of 15 rated as effective by the judges. The average score (mean of means) for the 64 children was 7.50 , ranging from 2.00 to 12.66 . The 64 children were divided at the median score of 7.66 into 32 high-skill $(M$ $=109.66$ for IQ) and 32 low-skill $(M=105.63$ for IQ) encoders. Of the 32 high-skill encoders, 10 were from third grade and 22 from fifth grade; 17 of them were male and 15 female.

\section{Naturalistic Communication}

\section{Participants}

The same 64 children were paired by matching members of each dyad as far as possible in terms of: (a) grade (16 dyads from third grade and 16 dyads from fifth grade); (b) age; (c) intelligence (the difference in IQ between two members of a dyad was $M=3.94$ and $S D=2.69$ for $3^{\text {rd }}$. graders, and $M=2.75$ and $S D=2.27$ for $5^{\text {th }}$-graders); (d) sex (15 male, 15 female, and 2 mixed dyads); (e) class group; and (f) type of encoder on the Word Pairs task (12 high-skill, 12 low-skill, and 8 mixed dyads).
Task

A Lego-set was displayed inside an open transparent container on a work table, in front of which both children were seated. Lego is a construction material made up of small pieces of plastic that can be assembled to build houses, etc.

\section{Procedure}

Participants were called, two at a time, to a room in the school equipped with a tape recorder and a video camera, both hidden to avoid creating an artificial situation. One of the aims was that children talk and behave spontaneously while performing a natural task (which all the children had done before). So the observer instructed children as follows: "Now you can play for a while and when I come back I want you to tell me if you have enjoyed the game and what you have built." Then the observer left the room. This moment signaled the start of the transcription, which lasted for 8 minutes per dyad. The observer performed the transcription on the basis of the audio and video tapes from the 32 dyads. The first child to speak after the door was closed was called interlocutor $A$, and the second one interlocutor $B$.

\section{Category System}

The same category system that was devised by Girbau (2002b) was applied to the transcripts by the first author (see Table 2). For readers' convenience, we reproduce the full description of this system below (see Categorization Unit). For the segmentation in units, the agreement index between two judges (Pearson's coefficient) was $r=.91, p$ $<.001$. For the categorization, the concordance index (Cohen's kappa) between two judges was $k=.80, p<.01$, which, according to Fleiss (1981), is an excellent criterion. Both indexes were based on 4 dyads from the sample.

Categorization unit. The categorization unit was defined as: (a) external verbal production by means of words or sounds (including shouting, audible non-overlapping laughter, feigned weeping, whistling, and sighing); or (b) clearly communicative gestures in substitution of a verbalization that would correspond there (only considered as such when the gesture responded to a request for information or for action, being transcribed sequentially at the moment the gesture started); or (c) silence (a pause of 2 or more seconds, during which neither of the two previously mentioned units appeared).

As to the criteria for segmentation into units, at least one of the following conditions had to be fulfilled: (a) a change of turn -the shift of interlocutors always signaled a new unit; (b) a category change -when, within the same turn, two or more categories were recognized (according to the operative definitions below), each of them was coded. 
Table 2

Category System

\begin{tabular}{|c|c|c|c|c|}
\hline \multirow[b]{2}{*}{ Social Speech } & \multicolumn{2}{|c|}{ Form } & \multicolumn{2}{|l|}{ Content } \\
\hline & Audible & & $\begin{array}{l}\text { Task-irrelevant } \\
\text { Task-relevant }\end{array}$ & $\begin{array}{l}\text { [IrAuSo] } \\
\text { [ReAuSo] }\end{array}$ \\
\hline & Audible & & $\begin{array}{l}\text { Task-irrelevant } \\
\text { Task-relevant }\end{array}$ & $\begin{array}{l}{[\mathrm{IrAuPr}]} \\
{[\mathrm{ReAuPr}]}\end{array}$ \\
\hline Private Speech & $\begin{array}{l}\text { Inaudible } \\
\text { Silent }\end{array}$ & $\begin{array}{l}\text { [InauPr] } \\
\text { [SilPr] }\end{array}$ & & \\
\hline
\end{tabular}

Note. From “A Sequential Analysis of Private and Social Speech in Children's Dyadic Communication” by D. Girbau (2002), The Spanish Journal of Psychology, 5, 110-119. Copyright by The Spanish Journal of Psychology.

If, upon one interlocutor's turn ending, there was silence (of 2 or more seconds), this was also coded, thus separating it from previous and subsequent utterances.

Operationalization of the categories. Categories were operationalized as (a) social speech, (b) private speech, or (c) untranscribable. Within the categories, according to their form, social speech could only be audible, whereas private speech could be audible, inaudible, or silent. Both audible social and private speech could be task-relevant or task-irrelevant.

Social speech (So). This was defined as a categorization unit (in terms of external verbal production or clearly communicative gestures as operationalized above) addressed to the play-partner (interlocutor). At least one of the following conditions had to be fulfilled:

1. Eye-contact simultaneously or immediately preceding or subsequent to a piece of information provided to the partner.

2. The verb is in second person singular or first person plural, addressing the partner.

3 . The interlocutor requests information or action (e.g., "look") from the partner.

4. The interlocutor initiates a new communicative exchange with the partner (e.g., giving the partner information).

5. The interlocutor repeats or reformulates a message addressed to the partner immediately or very soon after having sent a similar message.

6. The interlocutor requests the partner's attention by means of vocatives (e.g., "eh!”) or physical contact. The request must be accompanied by at least one of the other conditions, except when the interlocutor also shows an object to the partner, and the partner looks at it.

7. The interlocutor answers the partner's request for information or action.

8. The interlocutor completes a sentence initiated previously by the partner.
9. A categorization unit directly related to the information (private or social) provided by the partner immediately before or after, or very shortly before that categorization unit. It is usually a contribution to the conversation (although it may be just "yes," "no," or a laugh). It includes linguistic exchanges such as the interlocutory ritual (repetition of verbalizations by both speakers, which maintains a foreseeable regular rhythm), or interlocutory singing (partners alternately produce parts of the same song).

Audible (Au). Production volume (high, normal, or low) makes it intelligible to a listener, and it can be transcribed.

Task-irrelevant (Ir). Speech outside the given task construction play, neither directly related nor referred to the task. It includes allusion to (a) aspects of the environment (e.g., the weather) or the observer, unrelated to the task; (b) personal physical or psychological states that are not a direct consequence of the task (e.g., hunger); (c) personal experiences unrelated to the task; (d) Productions that are not a direct effect of the task, even if they are preceded by a task-relevant category.

Task-relevant $(\mathrm{Re})$. The content of speech refers to the task. It includes: (a) any mention of task materials or characteristics; (b) productions concerning problems, plans, procedures, and results of the task (e.g., counting the pieces); (c) allusion to task-related previous personal experiences or to the observer with regard to the task (e.g., possible performance time); (d) task-relevant fantasy; (e) productions that are a direct effect of the task (e.g., "good!," “mm”) and that sometimes may be a rhythmic accompaniment to task actions.

Private speech $(\mathrm{Pr})$. This categorization unit is not addressed or adapted to the listener, but to the speaker him- or herself. Sometimes, private speech is displayed in the reduction of voice volume; if volume was very 
low, speech was subcoded as inaudible. At other times, it is accompanied by great attention to the task. It includes: (a) speech addressed at an object, a phenomenon of nature, or an absent person (real or imaginary). The interlocutor addresses the object or person as if it were a human interlocutor (with a secondperson verb), ignoring the play-partner. There is therefore no eye-contact with the partner, either simultaneously or immediately before or after such speech; (b) an answer to a request for information formulated by the same participant in such a way that neither the request nor the answer initiates a new communicative exchange. Between the two utterances there could only be one other category at most, or two if one of them was silence. Request and answer were coded as private speech. Thus, if one of the utterances initiated a new communicative exchange (social speech) and the other did not (private), there would be two different categories.

Like social speech, private speech can also be categorized as audible, task-irrelevant, and task-relevant, which were defined above. It can also be inaudible and silent.

Inaudible (Inau). This subcategory refers to production in a very low voice, almost inaudible, and also made evident by lip movements. It follows the voice volume criterion: The voice was not loud enough to attribute any semantic content to the verbalization and was unintelligible to a very near listener.

Silent (Sil). A pause of 2 or more seconds during which none of the other categories appeared, so there was no external verbal production or inaudible lip movements and no clearly communicative gesture (as defined above).

Untranscribable (Unt). Unintelligible production due to recording conditions, defective audible vocalization, or whispering into partner's ear. If immediately before or after this untranscribable production, there was a unit that was intelligible but not categorizable due to unawareness of the content of the untranscribable production, this intelligible unit was also included in this category.

According to the above categorization system, social speech (always audible) could be categorized as task-irrelevant (IrAuSo) or task-relevant (ReAuSo). On the other hand, private speech could be categorized as inaudible (InauPr), silent (SilPr), audible and task-irrelevant (IrAuPr), or audible and task-relevant (ReAuPr). For example: "If you find one like this, give it to me." [ReAuSo]; "La, la, la, la, la, la." [IrAuPr].

\section{Results}

Data were analyzed from an interactive perspective, on the basis of 32 cases or dyads, as the 64 children were paired during the naturalistic communication. Communicative performance in the two tasks was compared by focusing on the frequencies of the speech categories used when playing with the Lego set by the different kinds of encoder dyads according to the Word Pairs. This would reveal the influence of this variable (dyadic type of encoder) on the frequency of those speech categories.

\section{Variability}

A total of 7170 categorized units was obtained during the sociolinguistic communication, from which the variability of the frequencies of the 7 speech categories was calculated with respect to the dyadic type of encoder and the dyadic grade (see Table 3 ). Concerning the total number of categorized units for dyads in the naturalistic context, there were no significant differences among the three dyadic types of referential encoder, who spoke with similar frequencies. Lastly, due to the very low incidence of untranscribable productions (Unt) in the whole sample $(1.5 \%)$, and given their defining characteristics, this category was excluded from the remaining calculations (comparative analyses of the variables).

\section{Comparative Analyses Concerning Both Tasks}

As the sex variable did not affect the number of highand low-skill encoders in the Word Pairs task and had a nonsignificant influence on the frequency of each category within the natural setting, data were regrouped independently of sex. Unit frequency was analyzed (by SPSS/PC+), taking into account three variables: speech categories (a total of 6), dyadic type of encoder (high-skill, low-skill, mixed), and dyadic grade $\left(3^{\text {rd }}, 5^{\text {th }}\right)$. Nonparametric statistics were applied to data as unit frequency is a discontinuous variable. All of the following comparisons were also analyzed with percentages and the same significances were found. In order to study the communicative performance of the same participants as seen from the two research approaches, comparisons were performed between: (a) the three types of encoder with respect to the 6 speech categories (18 MannWhitney $U$ tests); (b) both grades within each type of encoder with respect to the 6 speech categories (18 MannWhitney $U$ tests); (c) the 6 speech categories within each type of encoder (15 Wilcoxon matched-pairs signed-ranks tests for each type of encoder); and (d) the 6 speech categories within each combination of the levels of type of encoder and grade variables $(15 \times 3 \times 2$ Wilcoxon matched-pairs signed-ranks tests).

Mann-Whitney $U$ tests revealed two very interesting significant findings with respect to comparisons among types of encoder (see Figure 1). Specifically, task-relevant social speech (ReAuSo) was significantly more frequent in the communication between high-skill encoders than between low-skill ones $(U=29.5, p=.01)$, and more frequent in high-skill $5^{\text {th }}$-grade encoders than in high-skill $3^{\text {rd }}$-grade 
Table 3

Means, Standard Deviations, and Percentages of Speech Categories by Dyadic Type of Encoder and Grade

\begin{tabular}{|c|c|c|c|c|c|c|c|c|c|}
\hline \multirow{2}{*}{$\begin{array}{l}\text { Speech } \\
\text { Categories }^{\text {a }}\end{array}$} & \multicolumn{9}{|c|}{ Encoder Type and Grade } \\
\hline & Third $^{b}$ & Fifth $^{c}$ & Total $^{\mathrm{d}}$ & Third ${ }^{\mathrm{e}}$ & Fifthe & Total $^{\mathrm{f}}$ & Third $^{c}$ & Fifth $^{\mathrm{b}}$ & Total $^{\mathrm{d}}$ \\
\hline \multicolumn{10}{|l|}{ IrAuSo } \\
\hline$M$ & 44.33 & 11.33 & 36.08 & 15.00 & 36.25 & 25.62 & 19.67 & 11.22 & 13.33 \\
\hline$S D$ & 34.51 & 13.05 & 33.46 & 7.53 & 42.88 & 30.68 & 7.64 & 14.31 & 13.19 \\
\hline$\%$ & 22.33 & 4.75 & 17.30 & 7.01 & 14.37 & 10.99 & 9.39 & 4.65 & 5.71 \\
\hline \multicolumn{10}{|l|}{ ReAuSo } \\
\hline$M$ & 79.56 & 111.00 & 87.42 & 107.25 & 134.50 & 120.87 & 97.33 & 135.56 & 126.00 \\
\hline$S D$ & 37.21 & 44.23 & 39.56 & 17.40 & 61.59 & 44.36 & 7.77 & 26.20 & 28.44 \\
\hline$\%$ & 40.07 & 46.51 & 41.91 & 50.12 & 53.32 & 51.85 & 46.50 & 56.12 & 53.96 \\
\hline \multicolumn{10}{|l|}{$\mathrm{IrAuPr}$} \\
\hline$M$ & 11.11 & 9.33 & 10.67 & 19.75 & 18.25 & 19.00 & 7.00 & 11.44 & 10.33 \\
\hline$S D$ & 7.83 & 2.08 & 6.79 & 19.09 & 19.36 & 17.82 & 5.20 & 13.11 & 11.57 \\
\hline$\%$ & 5.60 & 3.91 & 5.11 & 9.23 & 7.23 & 8.15 & 3.34 & 4.74 & 4.43 \\
\hline \multicolumn{10}{|l|}{$\mathrm{ReAuPr}$} \\
\hline$M$ & 23.44 & 54.33 & 31.17 & 28.25 & 22.75 & 25.50 & 31.00 & 31.78 & 31.58 \\
\hline$S D$ & 13.96 & 21.36 & 20.49 & 14.75 & 10.37 & 12.17 & 7.94 & 5.95 & 6.11 \\
\hline$\%$ & 11.81 & 22.77 & 14.94 & 13.20 & 9.02 & 10.94 & 14.81 & 13.16 & 13.53 \\
\hline \multicolumn{10}{|l|}{ InauPr } \\
\hline$M$ & 10.67 & 25.00 & 14.25 & 13.75 & 19.25 & 16.50 & 17.00 & 23.89 & 22.17 \\
\hline$S D$ & 7.25 & 13.11 & 10.56 & 9.57 & 5.50 & 7.80 & 9.17 & 9.57 & 9.57 \\
\hline$\%$ & 5.37 & 10.47 & 6.83 & 6.43 & 7.63 & 7.08 & 8.12 & 9.89 & 9.49 \\
\hline \multicolumn{10}{|l|}{ SilPr } \\
\hline$M$ & 26.00 & 24.33 & 25.58 & 24.50 & 19.00 & 21.75 & 35.67 & 23.89 & 26.83 \\
\hline$S D$ & 10.12 & 5.51 & 8.98 & 8.50 & 17.03 & 12.80 & 6.03 & 13.83 & 13.20 \\
\hline$\%$ & 13.09 & 10.20 & 12.27 & 11.45 & 7.53 & 9.33 & 17.04 & 9.89 & 11.49 \\
\hline \multicolumn{10}{|l|}{ Unt } \\
\hline$M$ & 3.44 & 3.33 & 3.42 & 5.50 & 2.25 & 3.87 & 1.67 & 3.78 & 3.25 \\
\hline$S D$ & 3.09 & 1.53 & 2.71 & 3.11 & 0.50 & 2.70 & 0.58 & 2.82 & 2.60 \\
\hline$\%$ & 1.73 & 1.40 & 1.64 & 2.57 & 0.89 & 1.66 & 0.80 & 1.56 & 1.39 \\
\hline
\end{tabular}

Note. ${ }^{\text {a }}$ Labels for speech category abbreviations are as follows: IrAuSo $=$ task-irrelevant audible social, ReAuSo $=$ task-relevant audible social, $\mathrm{IrAuPr}=$ task-irrelevant audible private, $\mathrm{ReAuPr}=$ task-relevant audible private, $\mathrm{InauPr}=$ inaudible private, $\mathrm{SilPr}=$ silent private, Unt $=$ Untranscribable. ${ }^{\mathrm{b}} n=9$ dyads. ${ }^{\mathrm{c}} n=3$ dyads. ${ }^{\mathrm{d}} n=12$ dyads. ${ }^{\mathrm{e}} n=4$ dyads. ${ }^{\mathrm{f}} n=8$ dyads.

encoders $(U=2.0, p=.03)$. On the other hand, inaudible private speech (InauPr) was used more frequently by highskill encoders than by low-skill encoders, although the difference did not reach statistical significance $(p=.060)$.

With regard to the relative distribution of the speech categories, the significant comparisons concerning Wilcoxon tests (approached to $Z$ scores) are reported in Table 4. As can be seen, significant differences were found in the three types of encoder with respect to the speech category taskrelevant audible social speech (ReAuSo), which was always significantly more frequent than any of the five other speech categories. Four of these five categories also reached statistical significance in the subgroups of low-skill $3^{\text {rd }}$-grade and highskill $5^{\text {th }}$-grade encoders. For the remaining fifth category (IrAuSo), significance was observed for the high-skill $5^{\text {th }}$. graders encoders, but not for low-skill $3^{\text {rd }}$-grade encoders, although they showed a trend in the same direction.

Some significant differences were found only in highskill and low-skill encoders, but not in mixed ones. First, in both groups, task-relevant audible private speech (ReAuPr) was higher than inaudible private speech (InauPr) - as also in low-skill $3^{\text {rd }}$-grade encoders and high-skill $5^{\text {th }}$-grade onesand than task-irrelevant audible private speech (IrAuPr) also in the latter subgroup (high-skill $5^{\text {th }}$-graders). Second, the latter category (IrAuPr) was less prevalent than silence (SilPr) in both types (high and low-skill) of encoders and also in low-skill $3^{\text {rd }}$-grade students. More partially, significance was observed only in low-skill encoders, specifically in $3^{\text {rd }}$-grade students, for task-irrelevant audible social speech (IrAuSo) and silence (SilPr), which were 


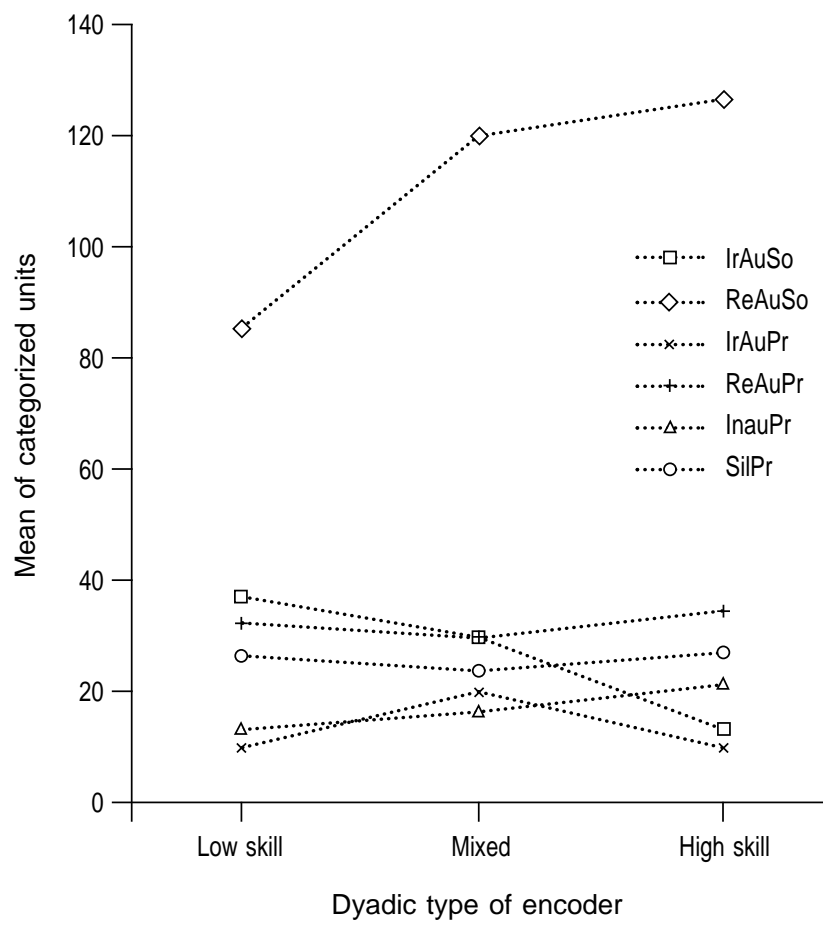

Figure 1. Mean of units for speech categories by dyadic type of encoder. respectively more frequent than task-irrelevant private (IrAuPr) and inaudible speech (InauPr). Similarly, there was significance only in high-skill encoders for inaudible (InauPr) and task-relevant audible private speech (ReAuPr), which were respectively higher than task-irrelevant private ( $\mathrm{IrAuPr}$ ) and social speech (IrAuSo) - in the latter case, also specifically in $5^{\text {th }}$-graders. Finally, low-skill $3^{\text {rd }}$-grade encoders used significantly more task-irrelevant audible social speech (IrAuSo) than inaudible private speech (InauPr).

\section{Discussion}

The first and main hypothesis of the present research was supported. All children of 8 and 10 years of age made use of speech that was not adapted to the decoder, in both referential communication (emitting inaccurate messages due to a nonadapted comparison process) and sociolinguistic communication (producing some external private speech in a dyadic context). However, in the experimental setting, $5^{\text {th }}$-grade students were generally more able to adapt to the decoder in the Word Pairs task than were $3^{\text {rd }}$-grade students, although none of the high-skill encoders reached the maximum of 15 effective messages (as it was 12.66). With regard to the naturalistic setting, there were no significant

Table 4

Significant Results of Speech Categories $\times$ Dyadic Type of Encoder $\times$ Dyadic Grade

\begin{tabular}{|c|c|c|c|c|c|}
\hline \multirow[b]{2}{*}{ Speech Categories ${ }^{\mathrm{a}}$} & \multicolumn{2}{|c|}{ Low-skill Encoders } & \multirow{2}{*}{$\begin{array}{c}\text { Mixed Encoders } \\
\text { Total }^{\mathrm{d}}\end{array}$} & \multicolumn{2}{|c|}{ High-skill Encoders } \\
\hline & Third $^{\mathrm{b}}$ & Total $^{\mathrm{c}}$ & & Fifth $^{b}$ & Total $^{\mathrm{c}}$ \\
\hline ReAuSo / IrAuPr & $-2.55^{*}$ & $-2.98^{* * *}$ & $-2.52^{*}$ & $-2.67^{* *}$ & $-3.06^{* * *}$ \\
\hline ReAuSo / ReAuPr & $-2.55^{*}$ & $-2.98^{* * *}$ & $-2.52^{*}$ & $-2.67^{* *}$ & $-3.06^{* * *}$ \\
\hline ReAuSo / InauPr & $-2.55^{*}$ & $-2.98^{* * *}$ & $-2.52^{*}$ & $-2.67^{* *}$ & $-3.06^{* * *}$ \\
\hline ReAuSo / SilPr & $-2.55^{*}$ & $-2.98^{* * *}$ & $-2.52^{*}$ & $-2.67^{* *}$ & $-3.06^{\text {**** }}$ \\
\hline ReAuSo / IrAuSo & - & $-2.27^{* * *}$ & $-2.38^{*}$ & $-2.67^{* *}$ & $-3.06^{* * *}$ \\
\hline ReAuPr / InauPr & $-2.67^{* * *}$ & $-3.06^{* * *}$ & - & $-2.10^{*}$ & $-2.00^{*}$ \\
\hline $\mathrm{ReAuPr} / \mathrm{IrAuPr}$ & - & $-2.59^{* *}$ & - & $-2.31^{*}$ & $-2.75^{* *}$ \\
\hline IrAuPr / SilPr & $-2.31^{*}$ & $-2.82^{* * *}$ & - & - & $-2.12^{*}$ \\
\hline IrAuSo / IrAuPr & $-2.31^{*}$ & $-2.27^{*}$ & - & - & - \\
\hline SilPr / InauPr & $-2.31^{*}$ & $-2.12^{*}$ & - & - & - \\
\hline InauPr / IrAuPr & - & - & - & - & $-2.00^{*}$ \\
\hline ReAuPr / IrAuSo & - & - & - & $-2.31^{*}$ & $-2.47^{*}$ \\
\hline IrAuSo / InauPr & $-2.07^{*}$ & - & - & - & - \\
\hline
\end{tabular}

Note. A dash indicates a nonsignificant result.

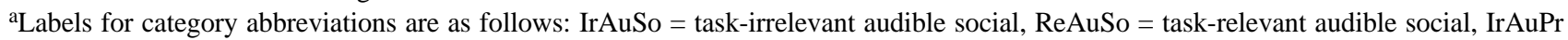
$=$ task-irrelevant audible private, $\operatorname{ReAuPr}=$ task-relevant audible private, InauPr $=$ inaudible private, $\operatorname{SilPr}=$ silent private. ${ }^{\mathrm{b}} n=9$ dyads .

${ }^{\mathrm{c}} n=12$ dyads. ${ }^{\mathrm{d}} n=8$ dyads.

${ }^{*} p<.05 .{ }^{* *} p<.01 .{ }^{* * *} p<.005$. 
differences in the kind of private speech used by the different types of encoders, despite an interesting trend towards significance for the inaudible form (InauPr). On the other hand, there were some significant results concerning the characteristics of social speech, which will be discussed below.

The second hypothesis focused on the internalization of private speech. In this case, there is only a trend for inaudible private speech (InauPr) to be higher in high-skill encoders than in low-skill ones; more research is needed to test this. This implies that: (a) high-skill encoders use inaudible speech significantly more often than task-irrelevant audible private speech (IrAuPr) and (b) inaudible speech is less frequent than silence in low-skill $3^{\text {rd }}$-grade students. It seems, then, that private speech tends to be internalized later in low-skill encoders, who emit many inaccurate and socially nonadapted referential messages, than in high-skill encoders. This category was also affected by age, as it was significantly more frequent at 10 than at 8 years of age (Girbau, 2002c), supporting Watson's (1919/1983) idea about the progressive internalization of private speech through whispering.

As to intrapersonal communication in general, inaudible private speech (InauPr) was significantly less frequent than task-relevant audible private speech (ReAuPr) in high-skill 10 -year-old encoders and low-skill 8-year-old encoders. This latter category (ReAuPr) also rose significantly above the task-irrelevant private speech ( $\mathrm{IrAuPr}$ ), in high-skill $5^{\text {th }}$ graders and in low-skill encoders as a whole. In fact, the audible form with task-relevant content (ReAuPr) is the kind of private speech that was preferred by the three types of dyadic encoder. All this reveals the importance of the task in hand within intrapersonal communication, that is, its appreciable external cognitive complexity at both ages, independently of the dyadic type of encoder.

The second most used category within the private speech categories by all three types of encoder was silence (SilPr), which was significantly more frequent than task-irrelevant audible private speech (IrAuPr) both in high-skill and lowskill $3^{\text {rd }}$-graders. This result is hardly surprising given the low incidence of the latter category (IrAuPr). However, the fact that silence was never the only kind of private speech used by children suggests that private speech was not totally internalized in any dyadic type of encoder.

The third hypothesis was also supported. In fact, the only category that was significantly affected by the variables type of encoder and age was task-relevant social speech (ReAuSo). When comparing the communicative performance in the two tasks, the dyads of high-skill encoders were observed to make significantly more use of cognitively complex social speech $(54.0 \%)$ than did low-skill dyads $(41.9 \%)$. In other words, the high-skill dyads showed more ability to simultaneously focus their attention on their interlocutor and on the task in hand (adapting both to the observer's request and the setting). Therefore, the better the referential skill of the children comprising the dyad, the better the sociolinguistic interaction between them when paired. But the influence of age on communicative quality was such that even the high-skill 10-year-olds were significantly more able to focus their productions on the task in hand and to consider their play-partner, than were the high-skill 8-year-olds ( $56.1 \%$ versus $46.5 \%$ ). This result is in accordance with the finding of a significantly higher incidence of that speech category (ReAuSo) in $5^{\text {th }}$-grade $(53.6 \%)$ than in $3^{\text {rd }}$-grade (43.9\%) students (Girbau, 2002c). Thus, such task-relevant social speech (ReAuSo) is significantly less frequent in low-skill encoders than in highskill encoders, in $3^{\text {rd }}$-graders than in $5^{\text {th }}$-graders, and in highskill $3^{\text {rd }}$-grade encoders than in high-skill $5^{\text {th }}$-grade encoders. The scarcity of previous research on this matter makes it difficult to compare the present results with more studies. However, from a different approach, there is evidence that significant changes occur in the quality of social speech when comparing similar ages, going from superficial to deep coordination processes, (Garrod \& Clark, 1993).

Similarly, task-irrelevant social speech (IrAuSo) tended to be more frequent in low-skill encoders than in high-skill encoders (17.3\% against 5.7\%), but the difference was not statistically significant $(p=.078)$. Significance was found in the same direction for $3^{\text {rd }}$ grade versus $5^{\text {th }}$ grade comparison (Girbau, 2002c). These results show that only low-skill $3^{\text {rd }}$-grade encoders produced significantly more task-irrelevant social speech (IrAuSo) than task-irrelevant private speech (IrAuPr) and inaudible speech (InauPr), and also that high-skill $5^{\text {th }}$-graders used significantly less social utterances not related to the task (IrAuSo) than task-relevant audible private speech (ReAuPr). So that seems to be a trend that again relates the high-skill communicative quality of the same participants in both tasks: the high-skill encoders in Word Pairs tended to use less task-irrelevant interpersonal communication (IrAuSo) than did low-skill encoders, who tended to use cognitively less complex social speech than did high-skill dyads. Moreover, the mean of this category (IrAuSo) for mixed-encoder dyads $(M=25.62)$ is the intermediate point between the means of the remaining types of dyadic encoders, that is, high-skill $(M=13.33)$ and lowskill $(M=36.08)$ encoders. In fact, in only one subgroup of a considerable size (the low-skill $3^{\text {rd }}$-grade encoders $[9$ dyads]) was task-relevant social speech (ReAuSo) not significantly higher than task-irrelevant social speech (IrAuSo). Here, the variables type of encoder and age act in a way that shows how a lower age and low-skill referential communicative adaptation to the decoder (laboratory task) affect the cognitive complexity of interpersonal communication (natural setting). Thus, the presence of such levels in those both variables (encoder type and age) was related to a decrease in the degree of cognitive elaboration in social communication.

On the other hand, sex did not affect the number of highand low-skill encoders in the Word Pairs task: Each sex group was comprised of approximately the same number of 
high- and low-skill encoders. In general, sex does not seem to affect referential communication performance (Dickson, 1982). Moreover, sex did not have a significant influence on the frequency of each category in the present naturalistic context. This result is in accordance with previous works on private speech, predominantly in a nonsocial context, which did not report any important influence of sex (Diaz \& Berk, 1992; Fuson, 1979). Therefore, both paradigms seem to indicate that the skill of adapting to the decoder is not affected significantly by sex.

Concluding, these results show evidence of a significant relation between measures of communication quality taken from a referential task and a dyadic naturalistic setting. The better the referential skill of the children comprising the dyad, the better the sociolinguistic interaction between them when paired. More research is needed to shed light simultaneously on the cognitive development of private and social speech from both paradigms, which, as this study suggests, are not as far apart from each other as they traditionally appear in the literature.

\section{References}

Asher, S.R., \& Oden, S.L. (1976). Children's failure to communicate: An assessment of comparison and egocentrism explanations. Developmental Psychology, 12, 132-140.

Asher, S.R., \& Parke, R.D. (1975). Influence of sampling and comparison processes on the development of communication effectiveness. Journal of Educational Psychology, 67, 64-75.

Berk, L.E., \& Garvin, R.A. (1984). Development of private speech among low-income Appalachian children. Developmental Psychology, 20, 271-286.

Boada, H., \& Forns, M. (Eds.). (1997). Perspectiva ecológica de la comunicación referencial. Anuario de Psicología, 75(4).

Cattell, R.B., \& Cattell, A.K.S. (1973). Measuring Intelligence with The Culture Fair Tests (4 ${ }^{\text {th }}$ ed.). (Spanish translation: Tests de factor " $g$ ", Escalas 2 y 3 Madrid: Tea,1986).

Cohen, B.D., \& Klein, J.F. (1968). Referent communication in school age children. Child Development, 39, 597-609.

Diaz, R.M., \& Berk, L.E. (Eds.). (1992). Private speech: From social interaction to self-regulation. Hillsdale, NJ: Erlbaum.

Dickson, W.P. (1981). Introduction: Toward an interdisciplinary conception of children's communication abilities. In W.P. Dickson (Ed.), Children's oral communications skills (pp. 133). New York: Academic Press.

Dickson, W.P. (1982). Two decades of referential communication research: A review and meta-analysis. In C.J. Brainerd, \& M. Pressly (Eds.), Verbal processes in children: Progress in cognitive development research (pp. 1-33). New York: SpringerVerlag.

Erickson, F. (1981). Timing and context in everyday discourse: Implications for the study of referential and social meaning. In W.P. Dickson (Ed.), Children's oral communication skills (pp. 241-269). New York: Academic Press.
Flavell, J.H. (1966). Le langage privé. Bulletin de Psychologie, 19, 698-701. (Originally presented at the Annual Meeting of the American Speech and Hearing Association, San Francisco, November 1964.)

Fleiss, J.L. (1981). Statistical methods for rates and proportions. New York: Wiley.

Fuson, K.C. (1979). The development of self-regulating aspects of speech: A review. In G. Zivin (Ed.), The development of selfregulation through private speech (pp. 135-217). New York: Wiley.

Garrod, S., \& Clark, A. (1993). The development of dialogue coordination skills in schoolchildren. Language and Cognitive Processes, 8, 101-126.

Girbau, D. (1996). Private and social speech in communication: Terminology and distinctive traits. Journal of Psycholinguistic Research, 25, 507-513.

Girbau, D. (2002a). Psicología de la comunicación. Barcelona, Spain: Ariel.

Girbau, D. (2002b). A sequential analysis of private and social speech in children's dyadic communication. The Spanish Journal of Psychology, 5, 110-118.

Girbau, D. (2002c). Private and social speech in children's dyadic communication in naturalistic context. Anuario de Psicología, 33, 339-354.

Girbau, D., \& Boada, H. (1996). Private meaning and comparison process in children's referential communication. Journal of Psycholinguistic Research, 25, 379-392.

Glucksberg, S., Krauss, R.M., \& Weisberg, R. (1966). Referential communication in nursery school children: Method and some preliminary findings. Journal of Experimental Child Psychology, 3, 333-342.

John-Steiner, V. (1992). Private speech among adults. In R. M. Diaz \& L. E. Berk (Eds.), Private speech: From social interaction to self-regulation. (pp. 285-296). Hillsdale, NJ: Erlbaum.

Kingsley, P. (1971, March). Relationship between egocentrism and children's communication. Paper presented at the meeting of the Society for Research in Child Development, Minneapolis.

Kohlberg, L., Yager, J., \& Hjertholm, E. (1968). Private speech: Four studies and a review of theories. Child Development, 39, 691-736.

Lloyd, P., Camaioni, L., \& Ercolani, P. (1995). Assessing referential communication skills in the primary school years: A comparative study. British Journal of Developmental Psychology, 13, 13-29.

Looft, W.R. (1972). Egocentrism and social interaction across the life span. American Psychologist, 78, 73-92.

Piaget, J. (1968). Le langage et la pensée chez l'enfant. Etudes sur la logique de l'enfant [The language and thought of the child] ( $7^{\text {th }}$ ed.). Neuchâtel, Switzerland: Delachaux et Niestlé. (Original work published 1923.)

Rosenberg, S., \& Cohen, B.D. (1964). Speakers' and listeners' processes in a word-communication task. Science, 145, 1201-1203.

Schober, M.F., \& Brennan, S.E. (2002). Processes of interactive spoken discourse: The role of the partner. In A.C. Graesser, M.A. Gernsbacher, \& S. Goldman (Eds.), Handbook of discourse processes (pp. 123-164). Mahwah, NJ: Erlbaum. 
Shantz, C.U., \& Wilson, K.E. (1972). Training communication skills in young children. Child Development, 43, 693-698.

Vygotsky, L.S. (1987). The collected works of L. S. Vygotsky: Vol. 1. Problems of general psychology. Including the Volume Thinking and Speech. (R.W. Rieber \& A.S. Carton, Ed.; N. Minick, Trans.). New York: Plenum Press. (Original work published 1934.)

Waters, H.S., \& Tinsley, V.S. (1985). Evaluating the discriminant and convergent validity of developmental constructs: Another look at the concept of egocentrism. Psychological Bulletin, 97, 483-496.
Watson, J.B. (1983). Psychology from the standpoint of a behaviourist. London: Frances Pinter. (Original work published 1919.)

Wertsch, J.V. (1985). Culture, communication, and cognition: Vygotskian perspectives. New York: Cambridge University Press. Yule, G. (1997). Referential communication tasks. Mahwah, NJ: Erlbaum.

Received November, 20, 2003

Revision received July, 20, 2004 Accepted July 30, 2004 